\title{
O LUGAR E O ENSINO DAS CIÊNCIAS NATURAIS NO TERCEIRO LIVRO DE LEITURA DE FELISBERTO DE CARVALHO (1892-1959)
}

\author{
Edna Pereira dos Santos Ferreira ${ }^{1}$ \\ Diane Valdez ${ }^{2}$
}

\section{Resumo}

Este trabalho é resultado de uma pesquisa de mestrado que investigou o ensino de Ciências Naturais (CN) no Terceiro Livro de Leitura de Felisberto de Carvalho, obra voltada para a Instrução Primária. O livro analisado faz parte da série de cinco livros seriados intitulados "Livros de Leitura", que circulou no Brasil desde a última década do século XIX até meados do século XX. O objetivo da pesquisa foi identificar, entre outros, a ênfase ao conhecimento científico, o ensino intuitivo, assim como a adequação do conteúdo às exigências da legislação educacional vigente. A pesquisa desenvolvida na perspectiva da História Cultural apontou que o ensino científico, pautado no ensino intuitivo, já defendido no Império brasileiro, prevaleceu na obra em detrimento de qualquer predomínio religioso e moral.

Palavras-chave: Terceiro Livro de Leitura. Ciências Naturais. Felisberto de Carvalho. História da Educação.

1 Mestra em Educação (UFG), assistente em Administração, Instituto Federal de Educação, Ciência e Tecnologia de Mato Grosso. E-mail: ednaroo@gmail.com

2 Doutora em Educação (Unicamp), professora da Faculdade de Educação da Universidade Federal de Goiás. E-mail: ufg.valdez@gmail.com 


\section{Introdução}

Este capítulo é um recorte da pesquisa de mestrado intitulada Introducção da Sciencia no Amago da Instrucçâo Primaria: O ensino de Ciências Naturais no Terceiro Livro de Leitura de Felisberto de Carvalho (1892-1959), realizada no Programa de Pós-Graduação em Educação na Faculdade de Educaçáo da Universidade Federal de Goiás, linha de Estado, Políticas e História da Educação, cuja temática abrange, na perspectiva da história cultural, as práticas e representaçóes dos livros de leitura seriados, com ênfase nos livros de Felisberto de Carvalho (FC).

A pesquisa teve por objetivo identificar a relação do ensino de Ciências Naturais e a legislação vigente no final dos oitocentos. Adotou-se, então, a História Cultural como aporte teórico-metodológico, uma vez que a pesquisa está inserida no campo da História da Educação, a fim de evidenciar como a história do objeto desta pesquisa, dentro da realidade social da época e de diferentes lugares, foi construída no período em que circulou.

Algumas questóes nortearam a pesquisa: $\mathrm{O}$ argumento de um ensino científico em detrimento de um ensino moral cristão prevalece nesta obra? O lugar ocupado pela área de Ciências Naturais, que incluía outras ciências, manteve o formato do livro de leitura, que tinha por objetivo ensinar a leitura para crianças das séries primárias?

A fonte principal utilizada foi o Terceiro Livro de Leitura e como fonte complementar o Decreto no 7.247/1879 (propôs a reforma do ensino primário e secundário no município da Corte e o superior em todo o Império) e o Parecer/Projeto de Reforma do Ensino Primário proposto pela Comissão de Instrução Pública (designada para analisar o decreto).

Desse modo, abordaremos as liçóes de Ciências Naturais no Terceiro Livro de Leitura de Felisberto de Carvalho, liçóes que perduraram no ensino desta área durante mais de meio século. Mapeamos o Terceiro Livro de Leitura em busca de traços e vestígios deixados pelo autor, a fim de buscar entender o lugar das $\mathrm{CN}$ nesta obra que ocupou um lugar relevante na sociedade brasileira desde a última década do período oitocentista perdurando até meados do século XX. 


\section{1 "Novas teorias, as novas classificações e as últimas descobertas": Noções de Sciencias Naturaes}

A fim de entender o contexto da sociedade desse período, buscamos na legislação (Decreto no 7.247/1879 e Parecer/Projeto de Reforma do Ensino Primário da Comissão de Instrução Pública) dados que nos permitam pensar como o livro que elegemos foi construído. Procuramos compreender ainda para quem os livros foram pensados, como o autor orienta adultos e crianças no uso do livro, uma série de fatos, a fim de entender o que nos dizem as fontes a respeito do lugar que os livros de leituras de FC ocuparam a partir da última década do século XIX, que significados e representaçóes o Terceiro Livro de Leitura evidencia:

As práticas culturais que aparecem na construção dos livros são tanto de ordem autoral (modos de escrever, de pensar ou expor o que será escrito), como editoriais (reunir o que foi escrito para construí-lo em livro), ou ainda artesanais (a construção do livro na sua materialidade, dependendo de estarmos na era dos manuscritos ou da impressão). Da mesma forma, quando um autor se póe a escrever um livro, ele se conforma a determinadas representaçôes do que deve ser um livro, a certas representações concernentes ao gênero literário no qual se inscreverá a sua obra, a representações concernentes aos temas por ela desenvolvidos. Este autor também poderá se tornar criador de novas representaçôes, que encontrarão no devido tempo uma ressonância maior ou menor no circuito leitor ou na sociedade mais ampla. (BARROS, 2003, p. 160).

Assim, como menciona o autor acima, os livros carregam consigo os 'modos de escrever, de pensar ou de expor o que será escrito' na visão do autor, por outro lado, os editores também deixam suas marcas na construção destes livros. Neste sentido, buscamos na representação deste livro de leitura, fonte impregnada de significados, uma vez que carrega consigo um período histórico de mudanças no sistema educacional brasileiro do final do século XIX. Busca-se, neste aspecto, as evidências, aquilo que não está explícito, investigar as entrelinhas, ressaltando a subjetividade e sensibilidades, uma vez que: 
Práticas sociais podem valer como discursos, silêncios falam, ausências revelam presenças, coisas portam mensagens, imagens de segundo plano revelam funçôes, canções e músicas revelam sentimentos, piadas e caricaturas denunciam irreverência, senso de humor e deboche. (PESAVENTO, 2014, p. 119).

De acordo com a mesma autora, o maior desafio é revelar os significados perdidos no passado, investigar evidências ocultas, questionar a fonte, analisar o contexto da época, enfim, desenvolver um trabalho semelhante a Sherlock Holmes. Para Burke (2005, p. 10), os historiadores culturais têm em comum “[...] a preocupação com o simbólico e suas interpretaçôes. Símbolos, conscientes ou não, podem ser encontrados em todos os lugares, da arte à vida cotidiana, mas a abordagem do passado em termos de simbolismo é apenas uma entre outras". São nessas perspectivas que nos orientamos.

As CN se destacam no Terceiro Livro de Leitura de FC, já na capa, com mais de dois terços das ilustraçóes, evidenciando a importância destas na Instrução Primária das crianças. Salientamos que as capas da série graduada de leitura de FC são plenas de ilustraçóes, significados e detalhes, uma vez que transportam representaçóes e significados de um período histórico da educação. No entanto, analisar essas ilustrações exige um outro estudo, uma investigação a partir da história da imagem, com outros referenciais teóricos. Seria viável e necessário fazer isso, no entanto, neste momento, não é nosso foco.

Ao tomar o livro de leitura, fonte escolhida, é possível perceber em seu contexto material de produção e formato de seus distintos vestígios que indicam formas e lugares de ensinar. Identificamos nos prefácios, notas, cartas e outros escritos registrados, a necessidade de inovaçáo para estar em consonância com a modernidade que, na maioria das vezes, importava-se da Europa. Em nota dirigida "Ao Público", os editores da obra do Terceiro Livro de Leitura ressaltaram a respeito da necessidade de 'refundir' a série de livros do autor em estudo:

Tendo-nos alguns professores indicado no Primeiro Livro de Leitura de Felisberto de Carvalho algumas faltas, taes como exercicios sobre as letras $\mathrm{Y}$ e $\mathrm{Z}$, resolvemos refundir inteiramente os cinco livros de leitura daquele autor, a fim de corresponder á aceitação contínua, que estes livros teem merecido (CARVALHO, 1911, p. 4). 
Felisberto de Carvalho faleceu no ano de 1898, no entanto, seus livros continuaram sendo editados por mais de seis décadas após sua morte. Carvalho viveu pouco para divulgar e modificar suas obras, diferentemente de outros autores que se ocupavam de propagandear seus livros, seja ocupando cargos públicos ou por meio das escolas que dirigiam. As poucas modificaçóes feitas após sua morte eram anunciadas ou justificadas conforme consta na passagem acima $^{3}$.

Diante da necessidade registrada, o livro que estamos analisando também sofreu modificaçóes:

Para este fim encarregámos os ilustres lentes da Faculdade de Medicina do Rio de Janeiro, os Drs Martins Teixeira e Oscar de Souza, de fazerem uma leitura destes livros; o primeiro revendo principalmente todos os assumptos sobre Physyca e Chimica, e o segundo tudo o que diz respeito ás Sciencias Naturaes, escoimando-os de qualquer expressão impropria que acaso tivessem, e pondo-os de acordo com as novas teorias, as novas classificaçôes e as últimas descobertas (CARVALHO, 1911, p. 4).

Nesta ressalva, temos uma primeira pista do que se considerava, ou melhor, do que não se considerava 'Sciencias Naturaes'. A proposta é investigar com mais rigor o que se fazia $\mathrm{CN}$ nesse momento, no entanto, ressaltamos que as áreas de estudo, matérias, disciplinas e currículos do período não estavam sincronizadas como hoje. Apesar da sincronia diferente, talvez mais afinada das áreas, este é um tema na história da educação que sempre causou, e causa, polêmicas, não é o objetivo discutir isso, mas é importante olhar para o passado com a observância da época.

Sobre a concepção polissêmica de disciplina na história da educação, Viviani (2007, p. 7) ressaltou:

Nesse sentido, é fundamental implementar a reflexão sobre as finalidades dos diferentes conjuntos de ensinamentos, bem como o processo dos processos de transformação das disciplinas, desde as suas gêneses até possíveis eventos de declínio ou expansão, de maneira a possibilitar o questionamento daquilo

3 Optamos por manter a grafia da época encontrada na fonte analisada. 
que comumente se caracteriza como tradição. Estas e outras questôes são objetos de estudo da história das disciplinas [...].

Podemos, a princípio, estabelecer relaçóes com os conteúdos encontrados e suas aproximaçóes. No entanto, a existência e as funçóes dessa área no plano do universo escolar do período de como, onde, de que forma, para que servia, expectativas e como se reorganizava são questóes elementares para a compreensão dos saberes que, aparentemente, não estáo a serviço exclusivo da educação. Os agentes externos devem ser considerados, pois em cada tempo as instituiçôes escolares tiveram finalidades nem sempre presentes nos programas e nas legislaçóes.

Por meio das fontes investigadas, não é possível apontar uma definição exata do que era o ensino das $\mathrm{CN}$ priorizado na obra, como toda escrita do passado, podemos cercar um pouco mais do que se compreendia por essa área, pois maior investimento no tema exigiria mais tempo e dedicaçáo no que a própria autora sugere como campo da história das disciplinas, o nosso recorte aqui é um livro de leitura destinado à Instrução Primária.

\section{Observar e treinar os sentidos: o ensino intuitivo nas lições}

Encaminhar a criança suavemente à natureza, conforme o que os pareceres apontavam na perspectiva do ensino intuitivo, pareceu-nos um indicativo apropriado para abordar as liçóes da obra escolhida. Para fundamentarmos nossa pesquisa, buscamos no Decreto Leôncio de Carvalho e no Parecer/Projeto da Comissão de Instrução Pública o porquê da ênfase às lições de coisas.

A lição de coisas, também conhecida como ensino intuitivo, estava presente na obra de FC, e é fundamentada no ensino por meio das coisas, ensinar as crianças antes de tudo a observar, para depois nomear, e por fim comparar, desenvolvendo assim os sentidos da criança.

No terceiro livro da série as $\mathrm{CN}$ representam a maior parte dos conteúdos abordados, pois o autor, possivelmente influenciado pelas ideias positivistas, oportunizou o conhecimento científico para o curso médio da Instrução Primária neste volume da série. Os temas abordados no Terceiro Livro de Leitura de FC ocupam quase $89 \%$ das liçóes, sem considerar a única lição de área afim, com tema relacionado à Física, e ultrapassariam 92\% dos conteúdos relacionados às $\mathrm{CN}$.

De acordo com Santos e Santos (2012), foi no século XVIII, na França e Inglaterra, que circularam as primeiras ideias que serviram de base para o 
positivismo que, como filosofia, estava relacionado às transformações da sociedade industrial europeia ocidental. A influência do positivismo no Brasil, a partir, sobretudo, da segunda metade do século XIX, se deu especialmente na exigência dos ideais republicanos que desafiaram a dominação católica e cultuavam o cientificismo.

$\mathrm{Na}$ tumultuada passagem do Império para a República, na tentativa da construção de uma nova ordem republicana, a influência do positivismo foi decisiva na escrita da história em propostas oficiais da educação, contribuindo na introdução do estudo do culto às ciências e na produção dos livros destinados às escolas.

Cremos não ser somente o autor da obra que analisamos que parecia estar em consonância com as ideias de culto às ciências, conforme pudemos observar na legislação do período, parece que a constituição do livro estava afinada com a perspectiva científica bem antes da Reforma Constant de 1890, que foi baseada nos fatos e na demonstração científica, sendo, de acordo com os mesmos autores, uma das principais consequências do positivismo no Brasil.

As lições ocupam em média sete páginas e meia, as quais discorriam o conteúdo abordado com o auxílio de ilustraçóes referentes ao tema e enfatizavam o ensino por meio do método intuitivo. Além disso, essas lições incentivavam o aprendizado através daquilo que é real e conhecido e desenvolviam a intuição da criança por meio da observação, treinando os sentidos, principalmente a visão e o ouvido.

São cento e quarenta e sete ilustraçôes distribuídas em vinte e sete liçôes, as quais abordavam sobre conteúdos diversos relacionados à Língua Portuguesa, Matemática e principalmente às $\mathrm{CN}$, este último ocupa aproximadamente cento e noventa páginas, restando dezessete páginas distribuídas em duas liçóes.

O conhecimento científico tem papel fundamental para a instrução das crianças, por isso acreditamos que tenha sido influenciado pelos estudos desenvolvidos pela Comissão de Instrução Pública (1883), o qual ressalta o ensino das Ciências, que deve inculcar na criança a observação, instigá-la a descrever aquilo que observa, comparando e criando conclusóes a partir de novas observaçóes, produzindo assim sua própria reflexão.

Salientamos a ênfase às $\mathrm{CN}$ neste terceiro livro que resultou em nossos questionamentos à obra, buscando analisar o destaque dado a esta área, bem como a organização e as prioridades de temas, o formato adquirido pelas 
lições e a distribuição de ilustraçôes. Assim, observamos que a obra é composta quase exclusivamente para o ensino do conhecimento científico, neste sentido, a Comissão de Instrução Publica traz importantes contribuiçôes:

O Estado tem deveres para com a sciencia. Cabe-lhe, na propagação della, um papel de primeira ordem; já porque do desenvolvimento da sciencia depende o futuro da nação; já porque a creação de fócos scientificos de ensino é de extrema dificuldade aos particulares; já porque entre a sciencia e varias profissóes, que entendem com a conservação dos individuos, a segurança material e a ordem juridica das sociedades, ha relaçóes: cujo melindre exige garantias, que só a interferencia do Estado será capaz de oferecer. (BARBOSA; ESPINOLA; VIANNA, 1883, p. 52).

Esta Comissão ressalta a importância do Estado na oferta do conhecimento científico à sociedade e os deveres deste com as ciências, devendo promovê-las, pois do desenvolvimento destas depende o futuro da nação. Apesar de a bibliografia encontrada enfatizar que os Pareceres da Comissão não entraram em vigor, acreditamos que FC possa ter sido influenciado pelas ideias propostas nos estudos da Comissão e o Decreto Leôncio de Carvalho (1879).

$\mathrm{O}$ autor priorizou dois principais temas no terceiro livro: 'animais' e 'vegetais', enfatizando continuamente a formação e utilidade para o ser humano. Também abordou temas como 'minerais', 'agronomia', 'anatomia e fisiologia humana', buscando ressaltar a importância do conhecimento científico para a formação e as formas de relacionar o assunto tratado com a realidade do aluno e da sociedade, como o cultivo e usos de alguns vegetais. Ao mesmo tempo em que propóe o ensino de $\mathrm{CN}$, se apropriou da forma de organização dos animais para comparar aos homens, além de aplicar o ensino da moral, como na lição 7a, intitulada "Formiga e Gafanhoto":

Dois grandes ensinamentos são os que desse modo nos dão as formigas: o primeiro é que o concurso do trabalho de muitos homens lhes permittirá a realisação do que a um só era impossivel; o segundo é que devemos auxiliar os nossos similhantes. (CARVALHO, 1911, p. 58). 
O uso de fábulas era recorrente nas liçóes dos livros de leitura desse período, uma vez que valia recorrer aos animais para dar liçóes de uniáo e coletividade no trabalho, além de ajustar os textos literários no sentido de harmonizar as relaçóes, o que faz evitar disputas e confrontos. Ademais, Carvalho se ocupou em transmitir ensinamentos morais de boa higiene, bons costumes e civilidade, ou seja, conceitos que imperam nas páginas em uma constante tentativa de formar, aos olhos da época, sujeitos dóceis, polidos e educados. Assim, insetos de toda espécie se tornavam personagens exemplares de trabalho incansável incentivando a dedicação e a relação com o outro de forma harmônica.

De acordo com Villela (2004), uma das características das obras de FC, sobretudo o Tratado de Metodologia e os livros seriados de leitura, é a vinculação de sua formaçáo religiosa ao avanço das CN. Para essa autora, FC faz questáo do conhecimento científico, entretanto, dissemina o discurso moralista no decorrer de suas obras. O Tratado de Metodologia, segundo a autora, pode estar relacionado a sua ligação ao pensamento da elite católica conservadora. Nesse mesmo sentido, Bezerra (2010, p. 200) registrou:

A obra didática de Felisberto de Carvalho está permeada de nuances entre as ciências e a religiáo. De um lado, ela atendia aos ditames legais, sobremaneira aqueles que se referem à formação religiosa de linha católica, que era a oficial do Estado [Pernambuco], na outra ponta estavam os ensinamentos científicos, as Ciências Naturais formando o arcabouço dos conhecimentos técnicos necessários à vida. Isto não impediu que Felisberto inserisse em suas obras valores como amor à pátria, a Deus, à família e ao próximo e mesmo preceitos de higiene [...].

Para Bezerra (2010), FC intercala em meio ao ensino das $\mathrm{CN}$ a religião, sendo a relevância das $\mathrm{CN}$ como uma base estrutural, entretanto, utiliza-se dos conteúdos abordados para incluir valores morais e cristãos. Para nós, este é um elemento que merece um olhar mais cuidadoso na obra estudada, o que pudemos perceber é que este autor segue ao contrário de Abílio Cesar Borges, católico por excelência, que fazia de seus livros de leitura uma extensão dos catecismos religiosos com perspectiva de ensino de leitura (VALDEZ, 2006). 
Em sua série de livros, FC não enfatizou qualquer conhecimento religioso, moral sim, mas religião não foi seu foco, destacou a importância do conhecimento científico na formação intelectual da criança, trabalhando desde a escola elementar a intuição. Na obra Tratado de Metodologia, afirma que o ensino intuitivo faz com que a criança desenvolva o espírito da observação, que origina os conhecimentos sólidos e duráveis. No Terceiro Livro, em especial, como já foi dito, encontramos duas pistas que apontam na direção moral da época.

O estudo desenvolvido por Bueno, Farias e Ferreira (2012) sobre as concepçóes do ensino de CN no início do século XX através do olhar do pedagogo alemão Georg Kerschensteiner evidencia que suas ideias surgiram num período de mudança, século XIX para o século XX, em um cenário em que o país passava por grandes mudanças educacionais. Fundamentados nas ideias do pedagogo alemão, estes autores salientam que:

[...] a aprendizagem das ciências naturais seria um componente essencial para o desenvolvimento do intelecto, pois, para compreender a mesma, não se faz necessário ter boa memória, visto que a essência da instrução lógica não consiste precisamente na assimilação de um conjunto de regras e de leis, mas em desenvolver processos mentais racionais que proporcionem a aplicação das leis científicas naturais aos problemas de investigaçáo, do conhecimento, da técnica da vida prática e da compreensão dos fenômenos. (BUENO; FARIAS; FERREIRA, 2012, p. 442)

Assim, as $\mathrm{CN}$ sobressaem em relação às demais áreas, importante na formação intelectual da criança, de modo que a aprendizagem das $\mathrm{CN}$ desenvolve as faculdades intelectuais proporcionando a 'aplicação das leis científicas e naturais', pois, segundo os autores mencionados, é papel da escola a educação do pensamento, já que, uma vez que feito isso, o próprio indivíduo buscará soluçóes para a vida profissional, familiar e em sociedade.

Conforme Bueno, Farias e Ferreira (2012), o ensino de $\mathrm{CN}$ por meio de levantamento de problemas proporciona ao aluno o desenvolvimento do hábito de pensar lógico, fazendo que este busque relacionar o conhecimento proposto aos fenômenos, formulando questionamentos concretos ao utilizar a prática da experimentação para comprovar ou refutar suas hipóteses. Corroborando esta ideia, a Comissão de Instrução Pública (1883) afirma que: 
O principio positivo, que pretende estender á escola a instrucção encyclopedica, amplial-a, como base, como estofo commum á educação da intelligencia humana, a todas as camadas sociaes, é incomparavelmente mais exequível do que os programmas escolares actualmente praticados entre nós. Insinuar, pelos methodos objectivos, no espirito da creança as noçóes rudimentares da sciencia da realidade, inocular-lhe na intelligencia o habito de observar e experimentar, é infinitamente menos arduo que martellar-lhe na cabeça, por meio de noções abstractas e verbaes, o cathecismo, a grammatica e a taboada. Num caso trata-se apenas de encaminhar suavemente a natureza; no outro, de contrarial-a systematica e brutalmente. [...]. (BARBOSA; ESPINOLA; VIANNA, 1883, p. 121).

A Comissão de Instrução Pública (1883) propõe a 'educação da intelligencia humanà incorporando noçóes científicas que partem da realidade, o que auxilia na inteligência do indivíduo inculcando-lhe o hábito de observar e experimentar, em vez de impor um conhecimento abstrato e distante da realidade. Também enfatiza a experiência em outros países, na qual evidenciaram que "[...] o curso escolar de sciencia é da mais grata amenidade para as creanças, constitue o único meio de crear entre ellas o gosto geral pela instrucção, e, por cumulo de bens, facilita o estudo dos outros assumptos" (1883, p. 186, grifo autor).

Os estudos em evidência reforçam a ideia de que a introdução das $\mathrm{CN}$ na Instrução Primária contribui para o desenvolvimento das faculdades intelectuais, proporcionando ao indivíduo observar, analisar, questionar, vivenciar e comprovar ou não o questionamento. Neste sentido, a Comissão ressalta que o cultivo das $\mathrm{CN}$ iniciado nos primeiros passos da educação elementar implanta no aluno o gosto pelos fatos, as relaçóes de causalidade, a ideia da lei que explica os fenômenos da criação. Salientam ainda que:

O mesmo papel de disciplina economica, si nos permittem a expressão, exerce o estudo das sciencias da natureza, que, expandindo prodigiosamente na creança as faculdades perceptivas, alhana o caminho a todos os trabalhos de especulação intellectual. Despertando, e educando uns poucos de sentimentos e disposições mentaes, que os methodos de hoje ignoram, e 
abafam, mas que formam a condição necessaria de todo o saber aproveitavel, a cultura scientifica desprende as azas que a natureza deu ao espirito da juventude, a que os processos vulgares atrophiam nas eternas andadeiras da rotina, creando ás intelligencias nascentes aleijōes incuraveis. (BARBOSA; ESPINOLA; VIANNA, 1883, p. 218, 219, grifo do autor).

No decorrer das lições observamos que FC usa o termo 'menino' com frequência e, segundo Valdez (2006), esse termo era comumente utilizado pelos autores de obras didáticas, visto que, com o passar do tempo, isso foi sendo substituído em decorrência do público ao qual se destinava a obra, passando a ser utilizado o termo 'infância' e 'criança'. Desse modo, o termo 'menino' se refere à criança do ensino primário e é muito frequente nos livros de FC, em que o autor chama atenção sobre a importância daquele conteúdo, para que possam observar a realidade e aplicar na vida em sociedade:

Eis ai, meninos, os principais instrumentos que se empregam para tornar a terra capaz de produzir. De outros, em diversos fins, se utiliza ainda a agricultura, como por exemplo da tesoura, que serve para cortar os galhos dos vegetais, e a grama, para o que se emprega também o alfange, que é uma lâmina recurvada [...]. (CARVALHO, 1911, p. 161, 162).

O trecho acima foi extraído da lição que trata dos instrumentos agrícolas, na qual o autor apresenta os principais instrumentos utilizados no manejo da terra e reforça sua importância para 'tornar a terra capaz de produzir', uma vez que continua descrevendo e explicando a função de cada um, sempre acentuando a atenção para o conteúdo em questão.

\section{Os Reinos da Natureza: suas utilidades, suas importâncias}

O levantamento realizado para o desenvolvimento desta pesquisa nos permitiu verificar que FC se utiliza dos reinos da natureza para ensinar às crianças a utilidade destes proporcionada aos seres humanos, uma vez que exemplifica os usos dos animais e vegetais na alimentação, na confecção de roupas, além da importância de sua utilidade para a indústria. 
Sobre isso, esclareceu Domingues (2009, p. 167, 168):

[...] No século XIX, o conhecimento da natureza confundiu-se à faina da exploração econômica dos recursos naturais. Com relação ao Brasil, a história das ciências tem sublinhado que, à época do Império, as ciências naturais foram subsídio dos seus esquemas de formação política, econômica e social. A conquista ou a dominação do espaço físico e o consequente conhecimento da natureza, que permitiu a exploração e o cultivo dos recursos naturais, resultaram de uma vontade política e, principalmente, dos conhecimentos adquiridos com as viagens empreendidas pelos naturalistas, que visavam o desbravamento do interior ainda desconhecido.

Neste sentido, notamos que 'o desbravamento do interior ainda desconhecido', com certeza para os naturalistas, resultou na exploração e cultivo das riquezas naturais brasileiras. Segundo esta mesma autora, a chegada da Coroa Portuguesa ao Brasil propiciou a institucionalização das $\mathrm{CN}$, tendo em vista a criação do Jardim Botânico e, consequentemente, a agricultura como base da economia brasileira.

De acordo com Domingues (2009, p. 170), “[...] Nessa época, o Brasil viveu a passagem da colonização política à colonização do meio natural, com tudo o que nele se incluía, mesmo os homens. As ciências naturais estavam na base dessa colonização do espaço natural”.

Assim, com a colonização do meio natural evidente no século XIX, percebemos no Terceiro Livro de Leitura que FC inclui a necessidade do conhecimento científico na Instrução Pública e, deste modo, as lições estão divididas em temas relacionados às $\mathrm{CN}$, sobretudo, abordando animais e vegetais, ou seja, nossas fauna e flora brasileiras.

FC organiza as primeiras liçóes da seguinte maneira: na primeira lição, aborda os sinais ortográficos; na segunda, o sistema métrico; na terceira, o autor trata sobre noçôes do corpo humano e as principais funçóes; na quarta lição, o autor introduz a divisão geral dos seres, com ênfase nos animais; e, na quinta, apresenta a divisão dos vegetais. Posteriormente, são organizadas numa sequência que intercala liçóes sobre os animais, vegetais e minerais, e, nas liçôes finais, o autor traz a utilização destes para o homem. 
Pelo que já tendes lido, conheceis, meninos, a grande divisão do reino animal e ainda alguns dos seres que fazem parte desse reino. Agora ser-vos-ão apresentados alguns outros que vos convem conhecer, e entre esses os principaes insectos de que uns nos maravilham por sua beleza, outros de tanta utilidade nos são, outros finalmente são nocivos e não poucos tambem asquerosos. (CARVALHO, 1911, p. 51).

Ao introduzir o tema de insetos, o autor deixa pistas sobre o objetivo do ensino das Ciências, ressaltando que alguns insetos atraem não somente devido à beleza, mas, sobretudo, a sua utilidade. Dessa forma, apresentam-se, aos meninos, os insetos que convêm pela beleza e utilidade, mesmo sendo 'nocivos e asquerosos'. A abordagem dos reinos animais classificados, ou considerados, 'uteis' e 'nocivos', perdurou nas páginas dos livros escolares até há pouco tempo. Assim, é interessante observar como os conceitos de todas as áreas das ciências vão sendo desconstruídos de acordo com novas pesquisas e estudos.

Nota-se nas demais liçôes que FC, ao caracterizar o animal e/ou vegetal, enfatiza, conforme as orientaçóes do período, suas utilidades e seus malefícios para os seres humanos. Ele também aborda os crustáceos, moluscos, dentre outros, retratando suas principais características e utilidades para o homem.

Observamos que FC aborda os assuntos das liçóes como forma de disseminar o conhecimento científico às crianças, mas, sobretudo, notamos a intenção do autor em evidenciar a utilidade deste conhecimento para a vida em sociedade, bem como revelando o modo para extrair os benefícios que os reinos da natureza podem fornecer ao homem, seja na alimentação, vestuário, na construçáo, dentre outros benefícios proporcionados. Isso funciona como uma espécie de roteiro de como viver de forma civilizada em relação harmônica com a natureza.

A organização do livro de FC foi alicerçada na classificação taxonômica dos seres vivos, de modo a agrupar as liçóes que versam sobre animais com características similares, assim como nas liçóes sobre vegetais. Tal classificação foi baseada na sistemática de classificação dos seres vivos proposta por Carolus Linnaeus (1707-1778), por meio da nomenclatura binominal, em que cada espécie recebe um nome em latim, formado por duas palavras, gênero e espécie. Sendo chamado nome científico, único para a espécie em qualquer 
parte do mundo, tendo em vista que o nome popular varia de uma região e/ ou país para outro, assim, cada espécie é sistematicamente classificada com base nas suas características.

O ensino de CN no Terceiro Livro de Leitura de FC tinha toda fundamentação embasada na sistemática de classificação do período, visto que os conteúdos/temas eram agrupados de acordo com características em comum, salientando a importância do conhecimento científico para a escola primária. Além disso, era enfatizado o conhecimento aliado à sua utilidade, bem como as formas de uso em benefício da sociedade, tendo em vista as riquezas naturais brasileiras serem uma fonte inesgotável para as investigaçóes científicas aliadas, sobretudo, à economia do país, conforme afirma Domingues (2016). Para esta autora, as expediçóes realizadas no século XIX, ao mesmo tempo em que foram práticas científicas, também foram a representação do processo político e econômico da expansão colonial e imperialista.

O século XIX representou grandes avanços nas $\mathrm{CN}$, como exemplo a publicação da obra baseada nos estudos de Charles Darwin e Alfred Russel Wallace, A Origem das Espécies, em que apresenta a Teoria da Evolução. Então, o conhecimento científico ganhou espaço de destaque em nível mundial. Certamente que todo esse movimento alcançou as páginas das obras didáticas, como pudemos constatar na fonte analisada.

Deste modo, notamos, no desenvolvimento deste trabalho, as $\mathrm{CN}$ como protagonistas na inserção do conhecimento científico para a Instrução Primária, visto sua importância para o desenvolvimento das faculdades intelectuais de observação, como afirma a Comissão de Instrução Pública (1883), é o primeiro modo de exploração científica, e, além disso, proporciona o desenvolvimento dos sentidos na criança.

Neste sentido, Felisberto destacou em seu Terceiro Livro de Leitura o ensino de $\mathrm{CN}$ como um conhecimento científico fundamental para o desenvolvimento da intuição na criança, entretanto, buscou também suprir a necessidade de material adequado e apropriado ao ensino, tendo em vista que o ideal para a Instrução Primária seriam os museus escolares com mapas e materiais que auxiliassem o ensino das liçóes de coisas, porém, na ausência destes, publicou seus livros aprovados pelo Conselho de Instrução Pública.

Por fim, a importância do conhecimento científico para FC ficou evidenciada ao introduzir as $\mathrm{CN}$ desde a escola elementar, inculcando na criança o saber científico, considerando as contribuiçôes do Decreto no 7.247/1879 
e Parecer/Projeto da Comissão de Instrução Pública (1883). Assim, o autor adotou o método intuitivo, a fim de que a criança aprendesse por meio das coisas, desenvolvendo a observação, incentivando-a a pensar, comparar, analisar e elaborar sua conclusão a respeito das observaçóes realizadas, sendo assim capaz de refletir o conteúdo ensinado.

Nossa pesquisa evidenciou as Ciências Naturais no âmago da Instrução Pública nas últimas décadas do século XIX e, apesar da ênfase do conhecimento científico no período republicado, este foi resultado da discussão de projetos que circularam no período imperial que foram normatizados pelo Decreto no 7.247/1879 e pela reforma proposta no Parecer/Projeto da Comissão de Instrução Pública (1883).

\section{Considerações finais}

A explosão do ensino de Ciências Naturais no século XIX decorreu em virtude da necessidade do conhecimento científico para a formação da criança, preparando-a futuramente para o trabalho em sociedade, uma vez que este saber científico tinha por base ensiná-la a aprender as utilidades das riquezas naturais brasileiras, a fauna e a flora.

As bibliografias consultadas revelam que Felisberto fazia parte da elite católica conservadora, porém não identificamos nos livros de leitura vestígios a respeito do ensino religioso. Entretanto, em determinados momentos, o autor utiliza-se dos exemplos da organização dos animais para exemplificar a moral e bons costumes para as crianças. A postura adotada pelo autor reforça a relevância do conhecimento científico para a Instrução Primária baseada no ensino intuitivo, de modo a desenvolver na criança a capacidade de observação, potencializando os conhecimentos sólidos e duráveis, conforme afirmou o autor.

Por fim, enfatizamos que as Ciências Naturais sem dúvida alguma ocupavam um lugar de destaque nos livros de leitura de Felisberto de Carvalho, introduzidas ao longo dos dois primeiros livros para dar lugar de destaque no terceiro livro para o conhecimento científico no ensino primário, de modo que ensinava-se a utilizar deste conhecimento com base na realidade em que viviam, tais como: de que forma se utilizar de um vegetal na produção de alimentos para o homem e os animais, ou na construção de materiais e equipamentos, dentre outros. 
Assim, os livros de leitura de FC são fontes preciosas para a história da educação e carregam grandes contribuiçôes, pois são livros que, apesar do período em que foram publicados, última década de oitocentos, tiveram ampla circulação no país, o que caracteriza sua aceitação no mercado editorial. As liçôes dos livros de FC tinham o poder de inculcar ideias e aprendizados tidos como importantes para a formação da criança, sempre fazendo referência do que era certo e errado, do que poderia ser ou não útil ao homem.

\section{REFERÊNCIAS}

BARBOSA, Ruy; ESPINOLA, Thomaz do Bomfim; VIANNA, Ulysses Machado Pereira. Reforma do Ensino Primário e várias instituiçóes complementares da Instrucçáo Pública. Comissão de Instrucção Pública. Rio de Janeiro: Typographia Nacional, 1883.

BARROS, José D'Assunçấo. História Cultural: um panorama teórico e historiográfico. In: Textos de História: Revista da Pós-Graduaçáo em História da UnB, v. 11, n. 1⁄2, 2003.

BEZERRA, Rozélia. A Higiene escolar em Pernambuco: os espaços da construção e os discursos elaborados. 2010. Tese (Doutorado)- Faculdade de Educação. Universidade de São Paulo, 2010.

BRASIL. Decreto n. 7.247, de 19 de abril de 1879 do Ministério do Império. Reforma o ensino primário e secundário no município da Corte e o superior em todo o Império. Coleção das Leis do Império do Brasil de 1879 - Parte II Tomo XLII. Rio de Janeiro: Tipografia Nacional, 1880. p. 196-217.

BUENO, G. M. G. B.; FARIAS, S. A.; FERREIRA, L. H. Concepçóes de ensino de ciências no início do século XX: o olhar do educador alemão Georg Kerschensteiner. Ciência \& Educaçáo, v. 18, n. 2, p. 435-450, 2012.

BURKE, P. O que é História Cultural? Rio de Janeiro: Jorge Zahar Editor, 2005.

CARVALHO, Felisberto de. Terceiro Livro de Leitura. 34. edição. Rio de Janeiro: Francisco Alves \& Cia, 1911.

. Tratado de Metodologia. 3. edição. Rio de Janeiro: Livraria Francisco Alves, 1909.

DOMINGUES, H. M. B. As ciências naturais e a "cobiça” sobre a Amazônia. In: Christina Helena Barbosa (Org.). Histórias de Ciência e Tecnologia no Brasil. 1. ed. Rio de Janeiro: MAST, 2016, v. 1, p. 106-125.

. O homem, as ciências naturais e o Brasil no século XIX. Acervo, Rio de Janeiro, v. 22, p. 167-178, 2009.

PESAVENTO, S. J. História e História Cultural. 3. ed. Belo Horizonte: Autêntica Editora, 2014. 
SANTOS, R. M. S.; SANTOS, J. O. O Positivismo e sua influência no Brasil. Revista Brasileira de Filosofia e História, Pombal-PB, v. 1, n. 1, p. 55-59, jan.-dez. 2012.

VALDEZ, D. A representaçáo de infância nas propostas pedagógicas do Dr. Abílio César Borges: o baráo de Macahubas (1856-1891). 2006. Tese (Doutorado)- Unicamp, Campinas, SP, 2006.

VILLELA, H. O. S. Construtores de uma pedagogia “à brasileira”: Felisberto de Carvalho e Francisco Alves, um encontro gerador. In: I SEMINÁRIO BRASILEIRO SOBRE LIVRO E A HISTÓRIA EDITORIAL, Rio de Janeiro, 2004.

VIVIANI, Luciana Maria. A Biologia necessária: formação de professores e Escola Normal. Belo Horizonte/MG: Argvmentvm; São Paulo: FAPESP, 2007. 